\title{
Systemic and Nasal Delivery of Orexin-A (Hypocretin-1) Reduces the Effects of Sleep Deprivation on Cognitive Performance in Nonhuman Primates
}

\author{
Sam A. Deadwyler, ${ }^{1}$ Linda Porrino, ${ }^{1}$ Jerome M. Siegel, ${ }^{2}$ and Robert E. Hampson ${ }^{1}$ \\ ${ }^{1}$ Department of Physiology and Pharmacology, Wake Forest University Health Sciences, Winston-Salem, North Carolina 27157, and ${ }^{2}$ Department of \\ Psychiatry and Biobehavioral Sciences, University of California, Los Angeles, California Veterans Administration Greater Los Angeles Healthcare System/ \\ Sepulveda, North Hills, California 91343
}

\begin{abstract}
Hypocretin-1 (orexin-A) was administered to sleep-deprived (30-36 h) rhesus monkeys immediately preceding testing on a multi-image delayed match-to-sample (DMS) short-term memory task. The DMS task used multiple delays and stimulus images and effectively measures cognitive defects produced by sleep deprivation (Porrino et al., 2005). Two methods of administration of orexin-A were tested, intravenous injections $(2.5-10.0 \mu \mathrm{g} / \mathrm{kg}$, i.v.) and a novel method developed for nasal delivery via an atomizer spray mist to the nostrils (dose estimated $1.0 \mu \mathrm{g} / \mathrm{kg}$ ). Results showed that orexin-A delivered via the intravenous and nasal routes significantly improved performance in sleep-deprived monkeys; however, the nasal delivery method was significantly more effective than the highest dose ( $10 \mu \mathrm{g} / \mathrm{kg})$ of intravenous orexin-A tested. The improvement in performance by orexin-A was specific to trials classified as high versus low cognitive load as determined by performance difficulty under normal testing conditions. Except for the maximum intravenous dose (10 $\mu \mathrm{g} / \mathrm{kg}$ ), neither delivery method affected task performance in alert non-sleep-deprived animals. The improved performance in sleep-deprived animals was accompanied by orexin-A related alterations in local cerebral glucose metabolism (CMRglc) in specific brain regions shown previously to be engaged by the task and impaired by sleep deprivation (Porrino et al., 2005). Consistent with the differential effects on performance, nasal delivered orexin-A produced a more pronounced reversal of sleep deprivation induced changes in brain metabolic activity (CMRglc) than intravenous orexin-A. These findings provide strong evidence for the effectiveness of intranasal orexin-A in alleviating cognitive deficits produced by loss of sleep.
\end{abstract}

Key words: cognition; sleep deprivation; monkeys; orexin-A (hypocretin-1); intranasal delivery; local cerebral glucose utilization; reversed impaired performance

\section{Introduction}

Orexin-A (Hypocretin-1) is a potent sleep related peptide, released by specific neurons in the hypothalamus (Peyron et al., 1998; van den Pol et al., 1998; Horvath et al., 1999; Lee et al., 2005). Receptors for orexin-A are located on neurons in many different brain regions making it possible for this peptide, once released, to activate a large number of areas affected by sleep and sleep deprivation (Hagan et al., 1999; Bourgin et al., 2000; Kilduff and Peyron, 2000; Piper et al., 2000; Gerashchenko et al., 2001; Yoshida et al., 2001; Wu et al., 2002; Peever et al., 2003; Lee et al.,

Received Aug. 24, 2007; revised 0ct. 26, 2007; accepted 0ct. 28, 2007.

This work was supported by Defense Advanced Research Projects Agency (DARPA) Grants DAAD19-02-1-0060 (Army Research Office) (S.A.D., L.P.) and BAA 04-12-F9034, National Institutes of Health Grants DA00119 and DA06634 (S.A.D., L.P.), DA09085 (L.P.), and NS14610 and MH64109 (J.M.S.), and the Medical Research Service of the Veterans Administration (J.M.S.). We thank Michael Todd, Ashley R. Morgan, Kathryn Gill, Joshua Long, Joseph Noto, Santos Ramirez, Mack Miller, Michael Dunlap, James Daunais, Stephanie Rideout, Nancy Buchheimer, Kimberley Black, Holly Smith, and Lucy Fasano for technical assistance. DARPA has approved this manuscript for public release, distribution unlimited.

Correspondence should be addressed to Dr. Sam A. Deadwyler, Department of Physiology and Pharmacology, Wake Forest University Health Sciences, Medical Center Boulevard, Winston-Salem, NC 27157. E-mail: sdeadwyl@wfubmc.edu.

DOI:10.1523/JNEUROSCI.3878-07.2007

Copyright $\odot 2007$ Society for Neuroscience $\quad$ 0270-6474/07/2714239-09\$15.00/0
2005; Mileykovskiy et al., 2005; Vittoz and Berridge 2006), It has recently been shown that manipulation of this system via administration of a orexin antagonist can increase sleep in rats, dogs and humans (Brisbare-Roch et al., 2007). The loss of orexin cells has been shown to cause human and animal narcolepsy (Chemelli et al., 1999; Lin et al., 1999; Nishino et al., 2000; Peyron et al., 2000; Thannickal et al., 2000; Gerashchenko et al., 2001; Wu et al., 2002; Mieda et al., 2004). Orexin-A has been shown to produce arousal, increased attention, increased muscle tone and to counteract the effects of narcolepsy (Hagan et al., 1999; John et al., 2000; Siegel, 2004; Mileykovskiy et al., 2005). Orexin-A has been shown to cross the blood-brain barrier by diffusion (Kastin and Akerstrom, 1999; Kastin et al., 1999).

Because orexin cell loss causes narcolepsy and administration of orexin reverses some of the deficits of canine narcolepsy (John et al., 2000), administration of orexin might be hypothesized to relieve sleepiness caused by sleep deprivation. In the following report, the effects of administering orexin-A to monkeys engaged in a cognitive task after $30-36 \mathrm{~h}$ of sleep deprivation are described and the resulting changes in rates of local cerebral glucose metabolism (CMRglc) noted. This is the first instance in which orexin-A has been administered systemically to a primate. We 
have determined that orexin-A applied via intravenous (i.v.) or via nasal spray mist delivery can counteract the effects of sleep deprivation in nonhuman primates and that the intranasal route is more effective. Our findings suggest that intranasal orexin-A administration may be useful in counteracting the effects of sleepiness in sleep-deprived animals and humans, and perhaps in humans with narcolepsy (Peyron et al., 2000; Thannickal et al., 2000) and Parkinson's disease (Fronczek et al., 2007; Thannickal et al., 2007).

\section{Materials and Methods}

Subjects. All procedures were reviewed and approved by the Institutional Animal Care and Use Committee (IACUC) of Wake Forest University, and performed in accordance with established practices as described in the National Institutes of Health Guide for Care and Use of Laboratory Animals. Eight adult male rhesus monkeys (Macaca mulatta) weighing $(8.0-11.0 \mathrm{~kg})$ were used in this study. They were individually housed in stainless steel cages in temperature and humidity controlled colony rooms with lighting maintained on a 6:00 A.M/6:00 P.M. on/off schedule and fed a diet of monkey chow supplemented by fresh fruit to maintain daily monitored body weight. Fluid intake was restricted in time and amount such that a prescribed volume of an animal's normal daily fluid intake $(80 \mathrm{ml} / \mathrm{kg})$ was received either during the behavioral testing session, or within $2 \mathrm{~h}$ of being returned to the home cage.

Behavioral testing. Each monkey was exposed to six different testing conditions [Normal Vehicle, Alert orexin-A (i.v. and nasal), Sleep Deprivation, Sleep Deprivation + orexin-A (i.v. or nasal)], which required 11-14 test sessions for each of the eight monkeys. Animals were placed in a primate chair $1.5 \mathrm{~m}$ in front of an LCD-front-projection screen for daily testing on a multi-image visual delayed match-to-sample (DMS) task and performed 150-300 trials per session (Hampson et al., 2004; Porrino et al., 2005). Animals were trained to move a cursor tracked by a fluorescent marker attached to the back of the monkey's hand into the images by positioning the hand within a two dimensional coordinate system on the chair counter. Stimuli consisted of clip art images projected as $25 \mathrm{~cm}$ squares within a $3 \times 3$ position matrix onto a $1.0 \times 1.0 \mathrm{~m}$ display. All images were unique to a particular trial during a session and no image was exposed on more than on one trial per session. Responses to appropriate stimuli were rewarded with diluted fruit juice delivered via a sipper tube placed in front of the mouth. All animals were trained to a stable baseline on the DMS task in which delay varied randomly from 1 to $90 \mathrm{~s}$ on a given trial, and the number of non-match stimuli (images) varied randomly from 1 to 7 in the Match phase of the task. As shown previously performance accuracy varied directly with duration of delay and number of non-match images (\#images) presented in the Match phase (Hampson et al., 2004; Porrino et al., 2005). Sets of stimulus images were routinely changed every 2 weeks to maintain the trial-unique feature of each session. Animals performed the task on consecutive days each week.

Sleep deprivation procedure. Sleep deprivation consisted of 30-36 h of continuous sleep prevention and wakefulness supervised continuously by laboratory personnel as previously verified using EEG recordings of sleep architecture. On sleep deprivation nights animals were maintained in a cage separate from their home cage in a continuously lighted room and kept awake with videos, music, occasional treats, gentle cage shaking, and interaction with technicians (working in $3 \mathrm{~h}$ shifts) through the night, until the usual daily testing time the next day. After testing animals were returned to their home cage and allowed to sleep. In a previous investigation (Porrino et al., 2005) evidence was provided that changes in brain imaging correlates of local glucose utilization during the DMS task (see below) were consistent with simultaneously recorded EEG changes produced by $30-36 \mathrm{~h}$ of sleep deprivation. Hence, replication of the same brain imaging correlates of sleep deprivation in this study verified that each animal was tested in the same sleep loss condition as reported preciously. Intervals of $10 \mathrm{~d}$, mandated by IACUC regulations, were interspersed between sleep deprivation episodes for each animal. There were no residual effects of the $30-36 \mathrm{~h}$ sleep deprivation regimen on testing $24 \mathrm{~h}$ afterward at which time animals had returned to their normal sleep patterns.
Drug administration. Orexin-A was mixed in saline for intravenous injections and in sterile water for nasal application. For intravenous administration orexin-A (\#003-30; Phoenix Pharmaceuticals, Mountain View, CA) was dissolved in physiological saline as a stock solution of 200 $\mu \mathrm{g} / \mathrm{ml}$ which was then diluted in saline to inject 3 different doses of 2.5 , 5.0 and $10.0 \mu \mathrm{g} / \mathrm{kg}$ via an indwelling catheter placed in either the femoral or jugular vein using a glass syringe. The glass syringe was presoaked in $1 \%$ BSA, rinsed in Milli-Q water then dried at $60^{\circ} \mathrm{C}$ before use. Only the 5.0 and $10.0 \mathrm{mg} / \mathrm{kg}$ doses of i.v. orexin were administered to sleepdeprived animals. Nasal orexin-A was administered via an atomizer that was operated by a computer controlled pressure valve that regulated delivery in $50 \mathrm{~ms}$ epochs via a spray mist ejected from the tip of the atomizer that was placed within $5-10 \mathrm{~cm}$ of the animals face in the region of the nostrils. Two $50 \mathrm{~ms}$ spray bursts were delivered to animals on each occasion of nasal orexin-A administration immediately before behavioral testing. The concentration of orexin-A in the spray solution $(25.0$ $\mu \mathrm{g} / \mathrm{ml}$ ) was arrived at through preliminary investigations in two anesthetized monkeys comparing different doses of i.v. orexin-A that did not result in immediate increases in orexin levels in cisterna magna CSF measured by RIA (baseline orexin level: $71.7 \pm 1.3 \mathrm{pmol}$ vs $10 \mu \mathrm{g} / \mathrm{kg}$ i.v. dose: $67.8 \pm 0.6 \mathrm{pmol}$ ), with application directly to the nasal mucosa which produced increased levels of orexin in CSF $(155.6 \pm 6.2 \mathrm{pmol})$ in samples collected $10 \mathrm{~min}$ after application. Animals were thoroughly habituated to the spray delivery method by subjecting them routinely to similar sprays of saline or sterile water immediately before each days testing regardless of condition.

Statistical analyses. Statistics were performed on behavioral measures of percentage correct performance versus cognitive load and treatment in the DMS task as a repeated measures ANOVA using the SAS PROC GLM General Linear Model which allowed analyses in a repeated measures multifactor ANOVA, and the ability to compensate for unequal case numbers in the statistical model. Main effect factors in the design included Cognitive Load (overall, low load, high load), Orexin Dose (Saline vehicle, $2.5 \mu \mathrm{g} / \mathrm{kg}$ i.v., $5.0 \mu \mathrm{g} / \mathrm{kg}$ i.v., $10.0 \mu \mathrm{g} / \mathrm{kg}$ i.v., and $1.0 \mu \mathrm{g} / \mathrm{kg}$ intranasal) and Sleep Deprivation (alert, SD). PROC GLM calculated independent effects of Dose and SD as well as Dose $\times$ SD interaction against the repeated measures of Load, then calculated interaction terms for different levels of Load (overall, High and Low) with Dose and SD. Interaction terms of the three-factor ANOVA were calculated in two stages: Dose and SD (between subjects) and Load versus Dose with Load versus SD (within-subjects). Because the ANOVA was not completely balanced attributable to the fact that the $2.5 \mu \mathrm{g} / \mathrm{kg}$ i.v. Orexin dose was not tested under SD conditions; the $2.5 \mu \mathrm{g} / \mathrm{kg}$ i.v. data were omitted from betweensubjects tests of Dose and SD, and only included the $2.5 \mu \mathrm{g} / \mathrm{kg}$ i.v. in the within-subjects tests for the effects of Load. Individual post hoc tests consisted of linear contrasts (Neter and Wasserman, 1974) consisting of orthogonal pairwise comparisons across individual levels of the Load, Dose and SD factors. The experimental design was fully randomized with respect to i.v. doses of Orexin and Sleep Deprivation conditions. However, the procedures were not completely counterbalanced because the testing of nasal orexin-A occurred a minimum of 2 weeks after the i.v. drug testing, during which time each animal's performance was required to return to criterion (Alert) performance levels when administered nasal saline for control purposes before testing with nasal orexin-A.

Measurement of local rates of cerebral glucose metabolism. Measurements of rates of CMRglc were made in eight monkeys within four different test conditions: normal alert DMS task i.v saline; DMS task-Sleep Deprivation i.v. saline; DMS task-Sleep Deprivation + orexin-A (i.v. or nasal). All animals $(n=8)$ were acclimated to the PET scan sessions to the extent that performance was not influenced by the injection or blood collection procedures. On the day of the scan the monkeys were placed in primate chairs and received a 30 s injection of $3-5 \mathrm{mCi}$ of $\left[{ }^{18} \mathrm{~F}\right]-2$-deoxy2-fluoro-D-glucose (FDG). The DMS task was initiated 5-10 min later and was performed for a total of $40 \mathrm{~min}(80-100)$ trials while the FDG was incorporated and taken up by cells during performance in the DMS task. After $40 \mathrm{~min}$, animals were anesthetized with ketamine $(15 \mathrm{mg} / \mathrm{kg}$, i.v.) and transported to the PET scanner. After scan acquisition, monkeys were transported back to their home cages and continuously monitored until fully recovered. Effects of anesthesia and other factors associated 
with the PET scanning procedures were previously assessed and shown to not influence measures of isotope uptake (Porrino et al., 2005).

To calculate glucose uptake, tracer concentrations were measured in blood samples using an automated gamma well counter from three blood samples collected from the femoral vein at $10 \mathrm{~min}$ before tracer injection and 8 and 42 min after injection. A population-averaged FDG blood curve (calculated for monkey) was scaled to the measured blood curve for the time period from injection to the end of the PET scan (Takikawa et al., 1993). Data were transformed to CMRglc based on the operational equation (Sokoloff et al., 1977; Phelps et al., 1979). Rate constants ( $k 1, k 2$, and $k 3$ ) and lumped constant as determined in monkey by Kennedy et al. (1978), along with a $k 4$ value used in human studies (Phelps et al., 1979). PET scans were performed with a General Electric (GE) Advance NXi PET scanner with a resolution of $4.0 \mathrm{~mm}$ and consisted of a $5.0 \mathrm{~min}$ transmission scan acquired in 2D mode, followed by a 10.0 min emission scan acquired in 3D mode. The image reconstruction of the 3D data used the 3D-reprojection method with full quantitative corrections and smoothed using a $4.0 \mathrm{~mm}$ Gaussian filter transaxially and then segmented. Data were corrected for attenuation and reconstructed into 128 by 128 matrices using a Hanning filter with a $4.0 \mathrm{~mm}$ cutoff transaxially and a ramp filter with an $8.5 \mathrm{~mm}$ cutoff axially.

PET data were analyzed with Statistical Parametric Mapping (SPM99) software (http://www.fil.ion.ucl.ac.uk/spm/) implemented in MATLAB (MathWorks, Natick, MA). Reconstructed images for each scan from each of the 8 monkeys were coregistered to corresponding structural MR images obtained on a 1.5-T MR scanner (GE Medical Systems, Milwaukee, WI) using automated image registration (Woods et al., 1993) and then transformed spatially into a standard space with an FDG template for rhesus monkeys constructed in our laboratory based on procedures of Black et al. (2001). Resultant images were smoothed using a $2 \mathrm{~mm}$ isotropic Gaussian kernel with a voxel size of $1 \times 1 \times 1 \mathrm{~mm}$. Scans were normalized for differences in global activity by proportional scaling. Effects at each voxel were estimated according to the general linear model using the multisubject conditions and covariates option in SPM. Statistical maps were created for comparisons of the five different experimental conditions: Normal Alert saline (i.v. and nasal) versus Normal Alert Orexin (i.v. or nasal); Sleep Deprivation (i.v. and nasal) versus Normal Alert saline (i.v. and nasal); Sleep Deprivation saline (i.v. and nasal) versus Sleep Deprivation + Orexin-A (i.v. or nasal) and Sleep Deprivation + i.v. Orexin-A versus Sleep Deprivation + nasal Orexin-A. Exploratory analyses used a minimum voxel height (magnitude) threshold of $p<0.01$ and a minimum cluster size of 50 voxels. A region of interest (ROI) analysis was conducted including dorsolateral prefrontal cortex (DLPFC), medial temporal lobe (MTL), thalamus (Thal), and dorsal striatum (Str), selected based on previous analyses in these same contexts (Porrino et al., 2005). Spherical ROIs were constructed on a structural MR template using the MarsBaR toolbox contained in SPM. Statistical significance for the 4 comparisons described above was determined with a threshold value of $p<0.05$ corrected for the search volume. Areas of activation were displayed on a T1 weighted anatomic MRI template then identified with reference to standard atlases of the primate brain (Black et al., 2001).

\section{Results}

\section{Effects of orexin-A on DMS performance during normal and} sleep-deprived conditions

The propensity for orexin-A to alleviate the effects of sleep deprivation was examined by administering the peptide to monkeys that had been sleep deprived 30-36 h before testing in the DMS paradigm. To control for any effects of orexin not related to sleep deprivation, animals were administered orexin-A i.v. and tested in the alert state after their normal $12 \mathrm{~h}$ sleep cycle. For comparison orexin-A was administered either i.v. or via nasal spray 10 min before testing on the day after a single night (30-36 h total) of sleep deprivation in the same animals. Results are described below in relation to 1) effects of orexin-A on DMS performance in sleep-deprived monkeys and 2) comparison of orexin-A delivered via the two routes, intravenous or nasal spray. In addition

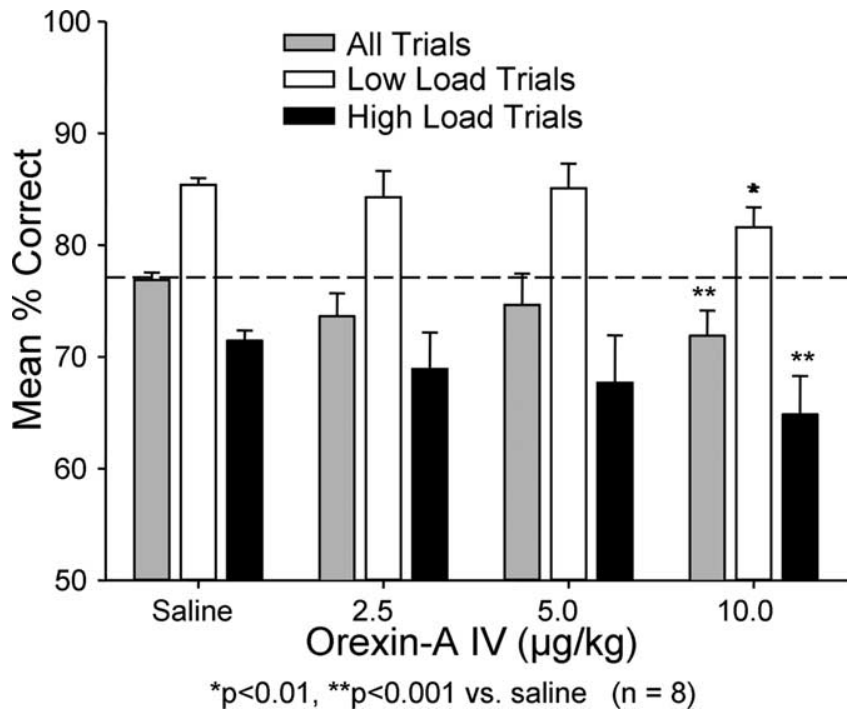

Figure 1. Effects of i.v. orexin-A on DMS performance in normal alert (non-sleep-deprived) monkeys. Three different dose levels $(2.5,5.0$, and $10.0 \mu \mathrm{g} / \mathrm{kg})$ of orexin-A were administered $10 \mathrm{~min}$ before the session at the normal daily testing time. Similar sessions in which i.v. saline was administered in the same manner as orexin are also shown. Overall performance is shown as mean \pm SEM for all trials (gray bars) and for low (cognitive) load (white bars) and high (cognitive) load (black bars) load trials. Horizontal line shows mean performance level over all saline trials for comparison of other means. ${ }^{*} p<0.01,{ }^{* *} p<0.001$ relative to similar trial categories in saline sessions.

the influence of orexin-A on local cerebral glucose metabolism (CMRglc) measured during performance of the task are presented corresponding to each of the above test conditions.

Performance of DMS task by alert (non-sleep-deprived) monkeys Performance of this version of the DMS task has been described in detail in previous publications (Hampson et al., 2004; Porrino et al., 2005) and was not different in the animals tested in this study except that delay parameters and number of distracter images in the "match" phase of the task were increased over the previously reported testing conditions. Performance in each DMS session was classified on the basis of trial rankings with respect to cognitive load (see Materials and Methods): long duration (60-90 s) trials with more distracter images (6-8) were defined as high cognitive load (high load) trials, whereas trials with short delays (1-15 s) and few distracter images (1-3) constituted low cognitive load (low load) trials. In addition, mean performance over all trials is also reported as shown in Figure 1 (Saline). DMS performance under alert normal conditions was assessed in animals tested after a standard sleep period ( $12 \mathrm{~h}$ light/ dark cycle) with saline vehicle administered either i.v. or via nasal spray 5-8 min before testing as shown in Figure 1 (Saline). Saline control (vehicle only) sessions were interspersed between orexin-A testing or sleep deprivation sessions within the same weekly testing period and at least one control session interspersed between each orexin-A test session. DMS performance under each condition was analyzed with a multifactor ANOVA with Dose and Sleep Deprivation as independent variables, and Cognitive Load as a repeated measure (see Materials and Methods). Results of the analysis reveled significant Main Effects of Load $\left(F_{(2,503)}=9.56, p<0.001\right)$ Dose (i.v. and nasal; $F_{(4,503)}=3.42$, $p<0.01)$ and Alert versus Sleep Deprivation conditions $\left(F_{(1,503)}\right.$ $=11.71, p<0.001)$. The analysis also tested the following Interactions: Load versus Dose $\left(F_{(8,503)}=2.96, p<0.05\right)$, Dose versus Sleep Deprivation $\left(F_{(4,503)}=4.08, p<0.01\right)$, Load versus Sleep 


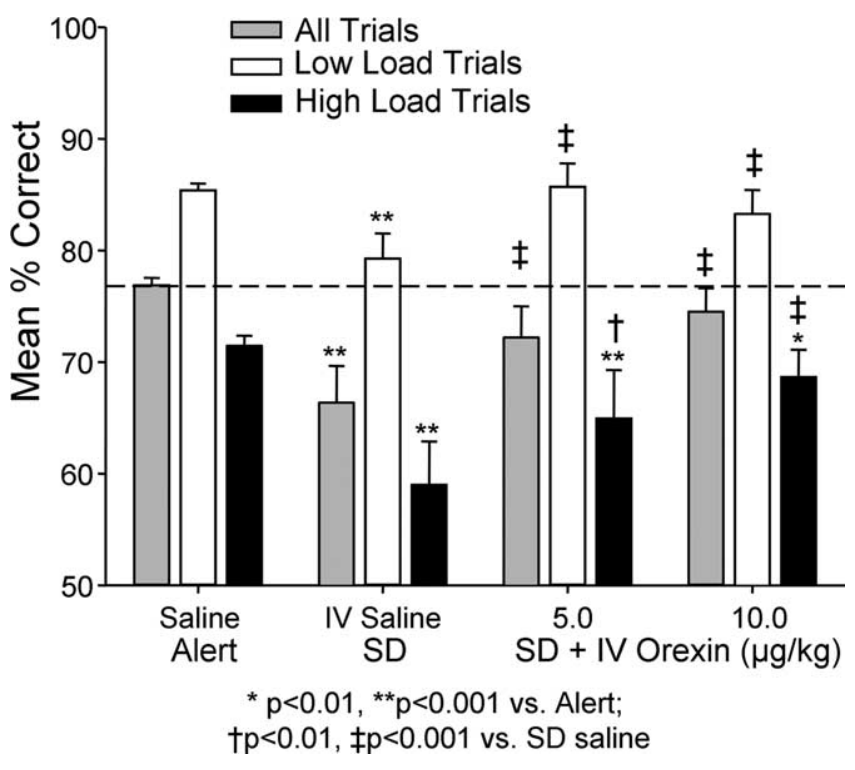

Figure 2. Effects of i.v. orexin-A on DMS task performance in monkeys sleep deprived for $30-36 \mathrm{~h}$. Performance was significantly impaired (SD, saline) compared with normal alert test sessions (Alert, saline). Intravenous orexin-A administered $10-15$ min before testing in sleepdeprived animals partially reversed the detrimental effects on performance (SD + IV Orexin, 5.0 and $10.0 \mu \mathrm{g} / \mathrm{kg}$ ). Trials were sorted according to cognitive load as in Figure 1. Horizontal line shows mean over all trials in normal alert saline sessions. ${ }^{*} p<0.01,{ }^{* *} p<0.001$ indicate comparisons with similar trial types in non-sleep-deprived saline sessions; ${ }^{\dagger} p<0.01,{ }^{\ddagger} p<$ 0.001 indicate comparisons between i.v. orexin- $A$ at different doses and i.v. saline sleepdeprived sessions.

Deprivation $\left(F_{(2,503)}=2.84\right.$, N.S. $)$ and the three-factor interaction of Load, Dose and Sleep Deprivation $\left(F_{(8,503)}=3.17, p<\right.$ $0.01)$. Given the significant Main Effects and Interactions, pairwise linear contrasts $\left(F_{(1,503)}\right)$ were performed on the means of individual conditions and reported in the following sections.

\section{Effects of systemic (i.v.) administered orexin-A on normal and} sleep-deprived DMS performance

Orexin-A was administered i.v. in three different doses $(2.5,5.0$ and $10.0 \mu \mathrm{g} / \mathrm{kg}$ ) to alert (non-sleep-deprived) monkeys immediately before testing. Figure 1 shows a dose-related trend toward reduced performance across all trial types as the dose increased from $2.5 \mu \mathrm{g} / \mathrm{kg}$, which reached significance at the $10.0 \mu \mathrm{g} / \mathrm{kg}$ dose level (Overall mean $10 \mu \mathrm{g} / \mathrm{kg}$ dose compared with saline control: $F_{(1,503)}=6.81, p<0.001$; Low-load trials: $F_{(1,503)}=5.77, p<$ 0.01 ; High-load trials: $\left.F_{(1,503)}=11.25, p<0.001\right)$.

The same monkeys were sleep deprived for $30-36 \mathrm{~h}$ then received intravenous injections of orexin-A immediately before their normal daily DMS testing time. As reported previously (Porrino et al., 2005) monkeys that were sleep deprived performed significantly worse than in normal alert conditions as shown in Figure 2 (alert versus sleep deprived) $\left(F_{(1,503)}=10.49\right.$, $p<0.001)$. Compared with the sleep-deprived i.v. saline condition, both doses of i.v. orexin-A ( 5.0 and $10.0 \mu \mathrm{g} / \mathrm{kg}$ ) significantly elevated performance in sleep-deprived animals (Overall: $F_{(1,503)}>15.96, p<0.001$; Low-load: $F_{(1,503)}>12.63, p<0.001$; High-load: $\left.F_{(1,503)}>6.92, p<0.01\right)$, however neither dose restored performance to that of the alert condition $\left(F_{(1,503)}<2.51\right.$, N.S.). Figure 2 also shows a differential effect of the i.v. orexin-A on high versus low cognitive load trials. Mean performance on low-load trials at both doses of i.v. orexin-A $(5.0$ and $10.0 \mu \mathrm{g} / \mathrm{kg})$ was similar to Alert conditions $\left(F_{(1,503)}=2.51\right.$, N.S. $)$. Although performance was significantly improved on high and low load

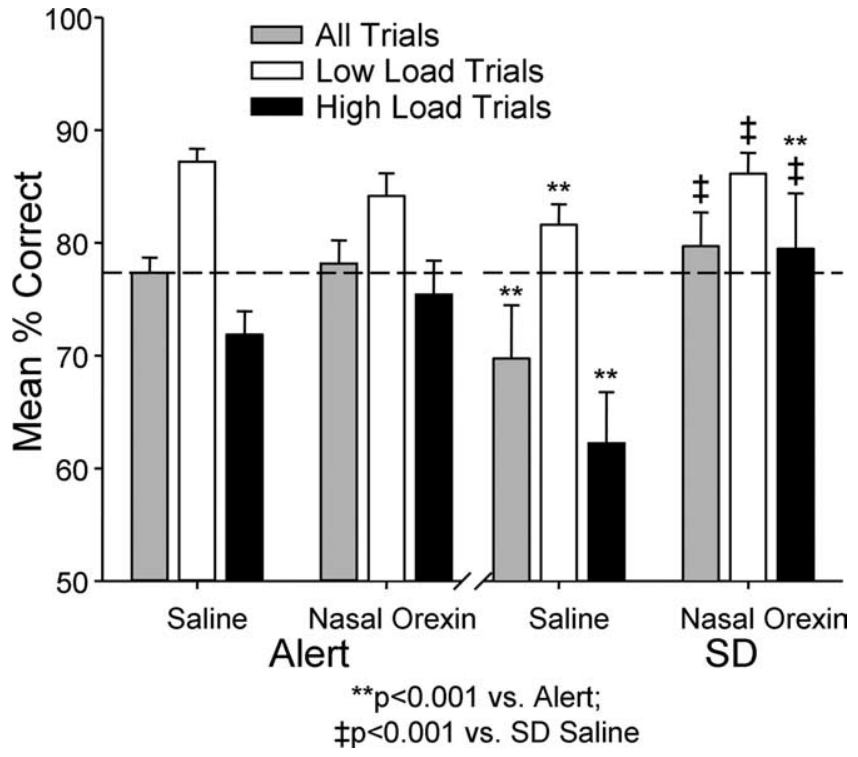

Figure 3. Effects of nasal orexin-A $(1.0 \mu \mathrm{g} / \mathrm{kg})$ on DMS performance of alert and sleepdeprived monkeys. Left, There were no significant effects of nasal orexin-A on mean percentage correct ( \pm SEM) performance over all trials. Low- or high-load trials, in the alert (non-sleepdeprived) condition. Right, Effects of 30-36 h sleep deprivation (SD) on performance of monkeys exposed to nasal saline or vehicle spray mist (Saline) 5-10 min before DMS testing. Application of nasal orexin-A spray $(1.0 \mu \mathrm{g} / \mathrm{kg})$ reversed the detrimental effects of $30-36 \mathrm{~h}$ sleep deprivation (SD) by significantly improving overall mean percentage correct ( \pm SEM) performance (SD, Nasal Orexin) as well as performance on low-load and high-load trials. ${ }^{* *} p<0.001$ compared with nasal saline alert; ${ }^{\ddagger} p<0.001$ compared with nasal saline sleep deprivation (SD).

trials for both doses $(5.0$ and $10.0 \mu \mathrm{g} / \mathrm{kg}$ ) of i.v. orexin-A relative to sleep-deprived i.v. saline sessions (i.v. orexin-A versus i.v. saline, $\left.F_{(1,503)}>7.01, p<0.01\right)$, high load trials showed a residual effect of sleep deprivation when compared with alert testing conditions (High-load: Alert. versus Sleep Dep: $F_{(1,503)}>6.88, p<$ 0.01 , for both doses).

\section{Effects of intranasal orexin-A on normal alert and} sleep-deprived performance

Orexin was mixed in a saline solution and sprayed in a mist through a pulsed pressurized atomizer held directly in front of the monkey's nostrils. The pulse duration was controlled by a computer and was set to $50 \mathrm{~ms}$. The concentration of orexin-A in the atomizer vial was $25 \mu \mathrm{g} / \mathrm{ml}$ and the estimated spray volume was $0.04 \mathrm{ml}$, yielding a delivered dose estimate of $1.0 \mu \mathrm{g} / \mathrm{spray}$. Two $50 \mathrm{~ms}$ duration sprays delivered 2-5 s apart aimed to within $5-10 \mathrm{~cm}$ of the animal's nostrils were administered 3-5 min before testing in both the alert normal condition, as well as after $30-36$ h of sleep deprivation. Each animal was thoroughly habituated to the procedure by administering a saline or sterile water only spray in the same manner as the orexin-A spray before every control (vehicle) session reported, including all nondrug sleep deprivation sessions. Because each animal received the same exposure to the vehicle spray over nearly all testing sessions, the spray containing orexin-A could be delivered in a consistent manner that was not different from vehicle sprays. All comparisons of normal alert and sleep-deprived sessions were with respect to vehicle versus orexin-A spray administered immediately before testing.

The effects of the nasal orexin-A spray in both normal alert and sleep-deprived sessions are shown in Figure 3. Nasal orexin-A had little or no effect on DMS performance under nor- 


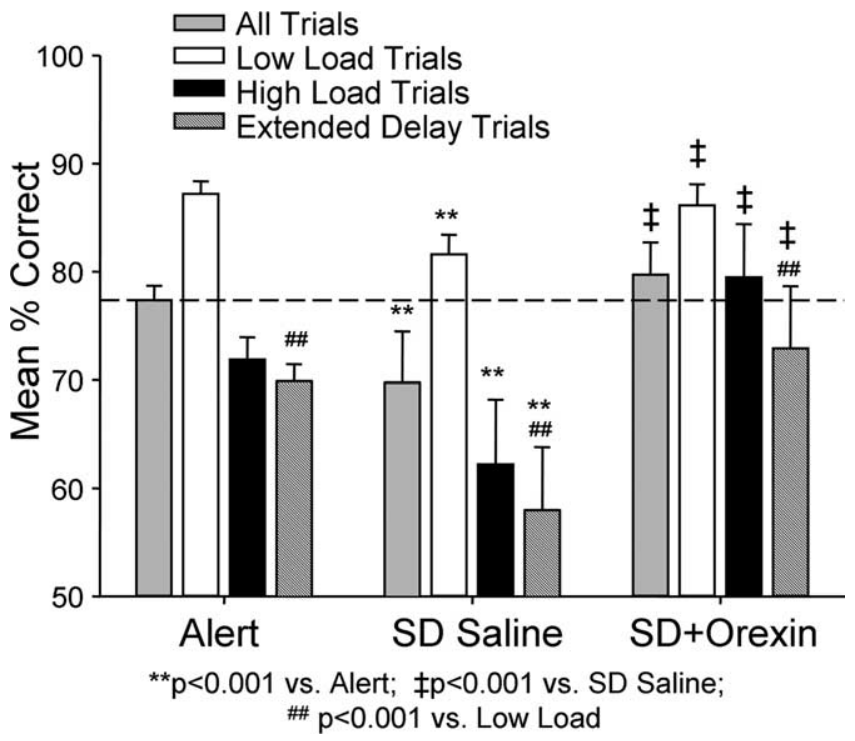

Figure 4. Effects of nasal orexin-A $(1.0 \mu \mathrm{g} / \mathrm{kg})$ on performance of extended delay trials in DMS task. Performance data in Figure 3 are plotted with mean percentage correct ( \pm SEM) performance on more difficult DMS trials with extended (90-120 s) delays (stippled bars). Performance on extended delay trials was significantly lower under all three conditions (normal alert, nasal saline sleep deprived and nasal orexin-A sleep deprived) relative to low-load trials in the same sessions ( $\left.{ }^{\# \#} F_{(1.503)}>32.91, p<0.001\right)$. Under sleep-deprived conditions, mean percentage correct $( \pm$ SEM) performance on extended delay trials after delivery of nasal orexin-A was significantly higher $\left({ }^{\ddagger} F_{(1,503)}=26.30, p<0.001\right)$ than extended delay, overall, or high-load trials in saline sleep deprivation sessions (SD Saline).

mal alert testing conditions. Neither was performance significantly altered on either low-load or high-load trials as was observed with i.v. orexin-A (Fig. 2). However, the surprisingly strong influence of nasal orexin-A in improving performance of the same monkeys when sleep deprived is shown on the right in Figure 4, and was in marked contrast to: 1) the effects of nasal orexin-A delivered in the same manner on normal alert sessions (Fig. 3, Alert), and 2) the lesser effect of i.v. orexin-A administered to the same group of animals when sleep deprived (Fig. 2). The nasal orexin-A spray reversed the detrimental influence of sleep deprivation on low-load trials by returning performance to normal alert levels $\left(F_{(1,503)}=8.19, p<0.01\right.$ versus SD. Saline; $F_{(1,503)}=1.14$, N.S. versus Alert Saline). More surprising however, nasal orexin-A elevated performance above normal alert levels on high-load trials $\left(F_{(1,503)}=9.07, p<0.001\right)$ which, compared with performance after control (saline) nasal spray in sleep-deprived animals $\left(F_{(1,503)}=17.53, p<0.001\right)$, constituted a considerable improvement (Fig. 3). To examine this latter effect in more detail, performance was compared on trials with extended delays of 120 s interleaved with regularly scheduled delays to further increase the difficulty (i.e., load) of High-load trials. Figure 4 shows the same data (as in Fig. 3) but with the extended delay trials added to indicate that performance on these type trials after nasal orexin-A exposure was also significantly above control sleep-deprived sessions $\left(F_{(1,503)}>22.36, p<0.001\right)$. The latter finding further indicates that the impact of the nasal orexin-A was more substantial on high-load difficult trials in sleep-deprived animals than trials of low cognitive load in the same condition (Figs. 3, 4).

For purposes of comparison, performance under sleepdeprived i.v. orexin-A and sleep-deprived nasal orexin-A sessions are plotted on the same graph in Figure 5. There was no significant difference in baseline sleep-deprived vehicle performance between the two test conditions. However, it is clear that the nasal
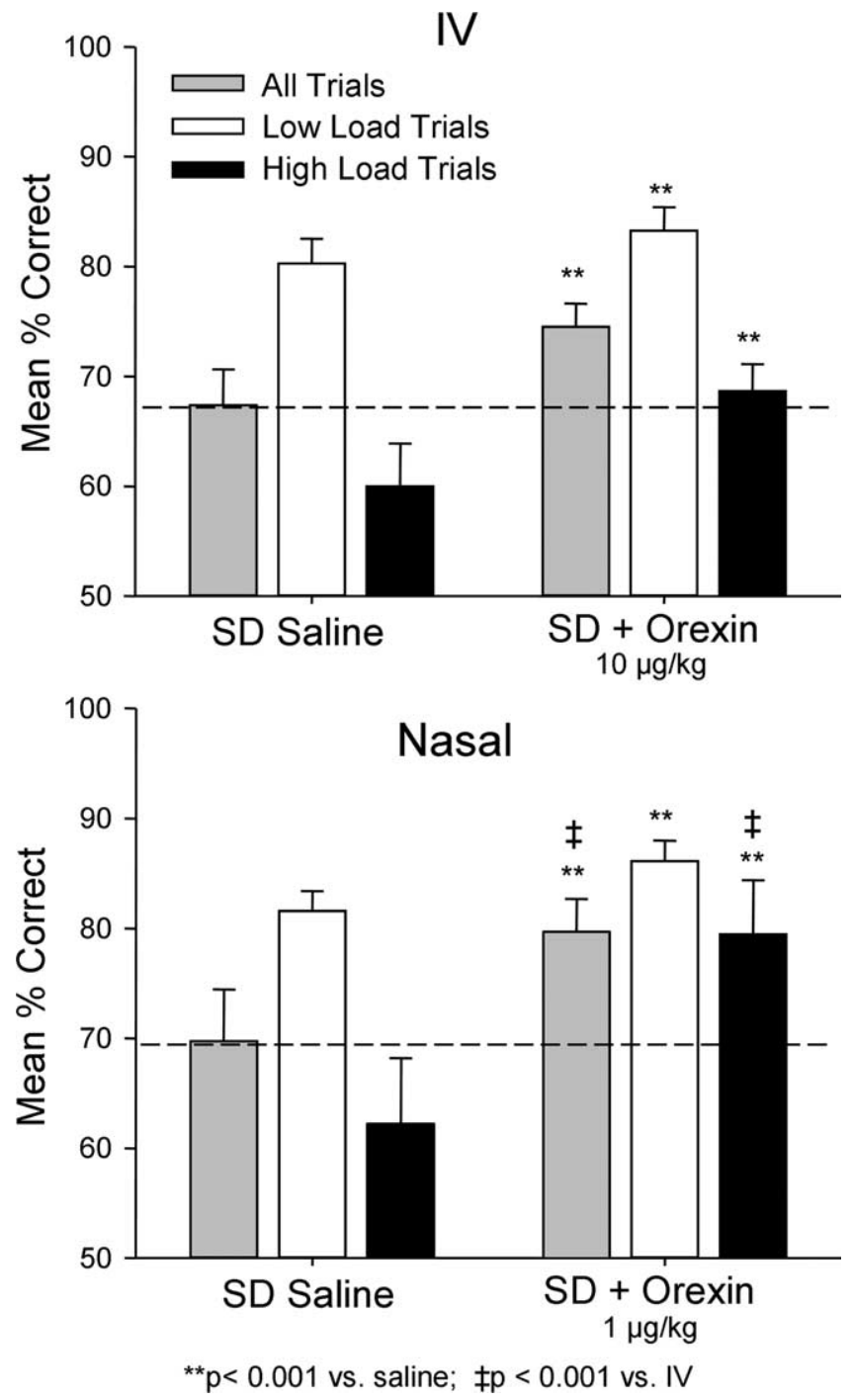

Figure 5. Comparison of i.v. orexin-A and nasal orexin-A on reversal of the effects of sleep deprivation (SD) on DMS performance. The same performance data as in Figures 1 and 3 are plotted to show comparison of effects of two delivery methods on mean percentage correct ( \pm SEM) performance relative to very similar saline sleep deprivation (SD) performance levels (dotted line). ${ }^{*} p<0.001$, difference relative to each respective saline sleep deprivation condition; ${ }^{\ddagger} p<0.001$, difference between i.v. versus nasal orexin A in sleep deprivation condition.

orexin-A spray was significantly more effective 1 ) on high-load trials (black bars) and 2) overall trials (gray bars), than the highest dose $(10.0 \mu \mathrm{g} / \mathrm{kg})$ of i.v. orexin-A $\left(F_{(1,503)}=17.49, p<0.001\right)$. Thus nasal administration of orexin-A, although estimated to be significantly lower $(1.0 \mu \mathrm{g} / \mathrm{kg})$ in dose, proved to be more potent than even the relatively high $(10.0 \mu \mathrm{g} / \mathrm{kg})$ dose of orexin-A delivered i.v. (John et al., 2000, 2003). Figure 5 demonstrates that nasal delivery of orexin-A was not only a selective means of increasing performance on high-load trials (i.e., there was no difference between i.v. and nasal orexin-A on low-load trials), but the increase was substantial enough to return mean performance across animals to normal alert levels which was not achieved by the highest dose of i.v. orexin-A.

Rates of local cerebral glucose metabolism during DMS task performance

All animals were assessed for changes in local cerebral glucose metabolism rates (CMRglc) associated with the reversal in cog- 
nitive performance deficits produced by the two methods of delivery of orexin-A (i.v. and nasal) to sleep-deprived monkeys. Statistical parametric maps using SPM5 software (University College London) were generated for comparisons of relative CMRglc across the 8 different monkeys used in the above cognitive tests. The ${ }^{18} \mathrm{~F}$ flurodeoxyglucose (FDG) isotope was injected immediately before each session and afterward animals were anesthetized and transported to the PET scanner within 90 min to image FDG uptake during performance of the DMS task.

\section{Effects of sleep deprivation on CMRglc}

In a previous study we provided comprehensive analyses of changes in local CMRglc in specific brain regions associated with performance of the DMS task and how task-related local CMRglc in those same areas was altered in monkeys that had been sleep deprived (Porrino et al., 2005). Sleep deprivation produced both increases and decreases in relative CMRglc in specific brain regions that were engaged during performance of the DMS task as shown in Figure 6 (left). Comparing CMRglc in the sleep deprivation condition with the normal alert task condition revealed significant decreases bilaterally in the dorsolateral prefrontal cortex (DLPFC; left: $t=$ 7.75, $p<0.001$; right: $t=4.61, p<0.01)$, and in the dorsal striatum (Str; left: $t=$ 3.24; $p<0.04$; right: $t=4.17 . p<0.013)$. In contrast significant increases in CMRglc occurred in the medial temporal lobe (MTL; left: $t=3.66, p<0.014$; right: $t=4.3, p<0.003$ ) in the same animals. In addition, a large decrease in CMRglc was observed in the thalamus (Thal; left: $t=6.11, p<0.003$; right: $t=$ $3.84, p<0.02$ ) during performance of the task in the sleep deprivation condition. All of the above changes in CMRglc in sleepdeprived monkeys were similar to those reported previously (Porrino et al., 2005).

\section{Effects of i.v. orexin on CMRglc in sleep-deprived monkeys}

Administration of the highest dose $(10.0 \mu \mathrm{g} / \mathrm{kg})$ of i.v. orexin-A to sleep-deprived monkeys produced significant changes in CMRglc in each of the brain regions affected by sleep deprivation during performance of the task. Local CMRglc in the DLPFC in the right hemisphere (Fig. 6, middle) was slightly elevated by i.v. orexin-A in sleep-deprived animals compared with levels that were decreased during sleep deprivation conditions (right: $t=$ 2.09, $p<0.047$ ). Similar increases from reduced i.v. saline sleep deprivation levels were observed bilaterally in the Str (left: $t=$ 5.01, $p<0.009$; right: $t=5.68, p<0.005$ ) and Thal (right: $t=$ 2.82; $p<0.03)$ in sleep-deprived animals injected with i.v. orexin-A $(10 \mu \mathrm{g} / \mathrm{kg})$. Significant decreases in CMRglc were observed in the MTL (right: $t=3.23, p<0.018$ ) in the sleepdeprived + i.v. orexin-A CMRglc $(10 \mu \mathrm{g} / \mathrm{kg})$ condition which constituted a directional change from elevated levels in i.v. saline sleep deprivation sessions (Fig. 6, middle bottom). Thus, DLPFC and Str showed significant increases during DMS task performance under sleep-deprived conditions after i.v. orexin-A (10 $\mu \mathrm{g} / \mathrm{kg}$ ), whereas MTL showed a significant decrease, which is consistent with previous findings showing changes in CMRglc associated with improvement in performance under sleepdeprived conditions (Porrino et al., 2005). However, the partial reversal of the effects of sleep deprivation in Thal by i.v. orexin-A $(10 \mu \mathrm{g} / \mathrm{kg})$ in sleep-deprived monkeys has not been observed in previous investigations from this laboratory.

Effects of nasal orexin on CMRglc in sleep-deprived monkeys

The administration of nasal orexin-A as a spray mist $(1.0 \mu \mathrm{g} / \mathrm{kg})$ to sleep-deprived monkeys also produced significant changes in CMRglc in each of the four brain regions affected by sleep deprivation in the same sessions in which performance was returned to normal alert levels (Figs. 3, 4). CMRglc in the DLPFC was significantly elevated bilaterally (Fig. 6, right) compared with nasal saline sleep deprivation sessions (left: $t=7.25, p<0.001$; right: $t=5.64, p<0.008)$. Similar increases were found bilaterally in Str (left: $t=9.33, p<0.001$, right: $t=4.48, p<0.02$ ) and Thal (left: $t=3.16, p<0.01$; right: $t=22.03$; $p<0.001$ ). As with i.v. orexin-A $(10 \mu \mathrm{g} / \mathrm{kg})$, significant decreases in CMRglc were observed in the MTL (left: $t=3.59, p<0.023$ ) relative to the sleep deprivation alone baseline condition. Thus, the pattern of CMRglc changes in the DLPFC, Str, MTL and Thal (Fig. 6, right) in sleep-deprived monkeys after administration of nasal orexin-A was similar to i.v. orexin-A, however the magnitude of the CMRglc changes were markedly different, consistent with the 
marked differences in the effects of the two methods of delivery on performance shown in Figure 5.

\section{Comparison of nasal versus i.v. orexin- $A$ on $C M R g l c$}

To directly assess differences in the routes of administration, the PET scans obtained in the same monkeys under i.v. orexin-A versus nasal orexin-A were compared by analyzing the differences in CMRglc between the respective drug delivery sleep deprivation conditions. Analyses of differences between the two delivery methods revealed that nasal orexin-A produced greater increases than i.v. orexin-A in CMRglc bilaterally in DLPFC (left: $t=3.54, p<0.05$; right: $t=7.18, p<0.003$ ), Str (left: $t=3.10$, $p<0.05$; right: $t=3.39, p<0.033$ ) Thal (left: 3.68, $p<0.035$; right: $t=3.52, p<0.05)$ as well as decreased CMRglc in MTL (left: $t=6.53, p<0.008$; right: $t=9.66, p<0.003$ ). Given the fact that both methods were compared in sleep-deprived animals, the results strongly suggest that the difference in potency for reversal of the sleep deprivation effects on regional CMRglc was the basis for the corresponding difference in degree of improved performance under sleep-deprived conditions (Fig. 5).

\section{Discussion}

The above results show that: 1 ) orexin-A, administered either intravenously (i.v.) or via nasal spray was an effective agent for reducing or reversing the effects of sleep deprivation on performance of the DMS task (Figs. 2-5), 2) Orexin-A delivered by both methods also significantly reduced or reversed changes produced by sleep deprivation on local brain CMRglc during performance of the DMS task (Fig. 6), 3) the nasal route of administration of orexin-A was more effective with respect to both of these effects than if administered i.v. (Fig. 5), and 4) neither i.v. nor nasal orexin-A produced facilitative effects if the animals were not sleep deprived. Moreover, by completely reversing the effects of sleep deprivation on high cognitive load trials and showing larger reversals of local CMRglc levels in brain regions engaged by the DMS task, delivery of orexin-A via the nasal route was also likely more potent because the nasal spray (estimated to be $1.0 \mu \mathrm{g} / \mathrm{kg}$ ) was only $\sim 1 / 10$ of the most effective i.v. dose $(10.0 \mu \mathrm{g} / \mathrm{kg})$. Another difference was the slight but significant performance impairment of i.v. orexin-A at the highest dose $(10.0 \mathrm{mg} / \mathrm{kg})$ in alert animals (Fig. 1) which was not observed with nasal orexin-A (Fig. $3)$. It is possible, because of this detrimental effect in alert animals, that the $10.0 \mu \mathrm{g} / \mathrm{mg}$ dose produced other side effects, which limited its ability to reverse the effects of sleep deprivation. However, the lower $5.0 \mu \mathrm{g} / \mathrm{kg}$ dose did not produce significant effects in alert animals and was effective in reversing the cognitive deficits in sleep-deprived animals. It is possible, therefore, that the action of orexin-A in alert animals, administered systemically at relatively high doses, may not be the same as when administered to the same animals when sleep deprived because of different levels of hypocretin-1 receptor activation (John et al., 2000; Hara et al., 2001; Kiyashchenko et al., 2002; Lee et al., 2005).

Orexin-A is a peptide found in all mammalian brains that have been examined. Orexin cells are localized to the hypothalamus (Peyron et al., 1998; van den Pol et al., 1998; Nambu et al., 1999; Kilduff and Peyron, 2000; Fadel and Deutch, 2002). Direct injection of orexin into the brain has been shown to increase alertness and muscle tone (Hagan et al., 1999; Bourgin et al., 2000; Piper et al., 2000). In addition several reports have demonstrated the correspondence between orexin-A release and the sleep-wake cycles of rodents, monkeys and humans (Edgar et al., 1993; Chemelli et al., 1999; Nishino et al., 2000; Taheri et al., 2000; Hara et al., 2001; Yoshida et al., 2001; Kiyashchenko et al.,
2002; Wu et al., 2002; Zeitzer et al., 2003; Lee et al., 2005). Orexin containing neurons are inactive in sleep and maximally active in waking states characterized by exploratory activity (Lee et al., 2005; Mileykovskiy et al., 2005). Recently, the importance of this endogenous system for sleep cycle regulation was demonstrated by the use of the selective orexin receptor antagonists, including ACT-078573 (Actelion Pharmaceuticals), in rodents, dogs, and man (Smart et al., 2001; Soffin et al., 2002; Brisbare-Roch et al., 2007; Rasmussen et al., 2007).

The results reported here support the above findings and show that systemically administered (i.v.) orexin-A exhibited some efficacy at relatively high doses $(10.0 \mu \mathrm{g} / \mathrm{kg})$ in alleviating the deleterious effects of sleep deprivation on cognitive performance (Figs. 2, 3). However, the relative financial expense and the lack of bioavailability of orexin-A coupled with drastically different potency when injected i.v. versus centrally (Kiyashchenko et al., 2001; Vittoz and Berridge, 2006) has precluded systemic orexin-A as a candidate for controlling the effects of sleep deprivation (Hara et al., 2001). We show here that these limitations can be greatly overcome by delivering orexin-A via nasal spray which proved superior to systemically delivered orexin-A both in terms of enhancing performance in sleep-deprived monkeys as well as reversing the effects on altered CMRglc levels in key brain areas affected by sleep deprivation.

The correlation between the effects of nasal orexin-A in reversing the effects of sleep deprivation on DMS task performance and the concomitant differential reversal of CMRglc changes in DLPFC, Str, and MTL associated with those performance deficits, is consistent with our previous findings which used the ampakine CX717 (Cortex Pharmaceuticals), a drug with completely different pharmacological actions, to demonstrate similar effects (Porrino et al., 2005). The most logical explanation for this is that orexin-A produced a reversal of the compensatory increase in MTL CMRglc associated with the loss of glucose utilization in DLPFC attributable to sleep deprivation. The decrease in MTL after orexin-A administration to sleep-deprived animals therefore reflected a reversal of the compensatory increase in MTL activity that occurred when DLPFC activity was reduced in sleepdeprived animals. It has been previously demonstrated that the reversal of these two conditions establishes the same relative increase in CMRglc levels in both regions exhibited when the animals perform the task under Alert (non-sleep-deprived) conditions (Porrino et al., 2005).

The correspondence in actions of the two compounds is supported by recent evidence showing that selective inactivation of orexin-A receptors in CA1 region of hippocampus impairs memory in rodents (Akbari et al., 2006). Another possible basis for the facilitation in performance by orexin-A was that, unlike CX717 (Porrino et al., 2005), orexin-A administered by both routes (nasal and i.v.) reversed the effects of sleep deprivation on CMRglc levels in the thalamus (Fig. 6), a brain region highly susceptible to sleep deficits in humans (Thomas et al., 2000; Drummond and Brown, 2001; Lambe et al., 2005). The fact that nasal orexin-A was effective in reversing performance on High-load trials, even to a greater extent than in normal alert sessions, suggests that: 1) high cognitive load trials engage either different brain processes or the same processes to a greater extent than low cognitive load trials, and 2) "high load cognitive processes" may recruit many neurons that have orexin receptors that can be activated more effectively by peptide delivery via the nasal route (Fig. 5). Support for this assumption is provided by the large differences produced by nasal orexin-A on CMRglc levels in DFPC, Str and MTL compared with i.v. orexin-A administration. Another positive control 
for the specificity of this effect was the fact that the same increase in CMRglc levels were observed in the thalamus as a function of either delivery method (Fig. 6, Thal).

Delivery of orexin-A via the nasal route has been reported previously to be more effective than i.v. administration in terms of peptide binding to orexin receptors in the CNS in anesthetized mice (Hanson et al., 2004). Inhalation has been shown to be an effective means of delivery for a number of peptides, which cannot be delivered effectively in blood because of excessive protein binding (McFarland and Beeson, 2002; Trombetta and Mellman, 2005). However the effectiveness of nasal orexin-A indicates that the nasal mucosa is a reliable means of delivery for the peptide to gain accessibility to important task-relevant brain processes whose CMRglc levels were completely reversed from the decreased levels produced by sleep deprivation. This was supported by our preliminary observations of marked differences in CSF levels of orexin measured within 10 min of delivery by the nasal route (see Materials and Methods).

The current findings provide additional evidence for the involvement of the sleep peptide orexin-A in the regulation of important cognitive processes that are affected by physiological perturbations such as sleep deprivation. The results demonstrate that orexin-A can reverse the cognitive performance deficits produced by sleep deprivation (Figs. 2, 4), as well as reverse regionally specific CMRglc levels in task-related brain regions (Fig. 6). This suggests that orexin-A has effects that go beyond mere global arousal, and may be involved in reactivating specific brain mechanisms required for optimal performance in a task requiring both attention and working memory (Hampson et al., 2004). The demonstration that orexin-A delivered via nasal spray in nonhuman primates is capable of reversing so many different behavioral and brain attributes affected by sleep deprivation provides a new basis for examining the actions of this and other brain peptides whose systemic delivery was heretofore not practical because of unknown interactions with constituents in blood and other absorption problems. Although it is possible that the reversal of the effects on sleep deprivation could be mediated via peripheral actions of nasal orexin-A on olfactory nerves or other neural processes (van den Pol, 1999; Kilduff and Peyron, 2000), the likelihood that such actions would affect the same brain regions (Fig. 6) as the ampakine CX717 (Porrino et al., 2005) tested in the same behavioral paradigm, is remote. Such investigation may reveal new opportunities to use orexin-A and other peptides in applications related to sleep, as well as in other types of brain disorders, via a much less invasive route of administration. In particular, nasal orexin-A administration may be an effective approach to the treatment of orexin deficiency in narcolepsy (Peyron et al., 2000; Thannickal et al., 2000) and in Parkinson's disease (Lee et al., 2005; Fronczek et al., 2007; Thannickal et al., 2007).

\section{References}

Akbari E, Naghdi N, Motamedi F (2006) Functional inactivation of orexin 1 receptors in CA1 region impairs acquisition, consolidation and retrieval in Morris water maze task. Behav Brain Res 173:47-52.

Black KJ, Koller JM, Snyder AZ, Perlmutter JS (2001) Template images for nonhuman primate neuroimaging. 2. Macaque. NeuroImage 14:744-748.

Bourgin P, Huitron-Resendiz S, Spier AD, Fabre V, Morte B, Criado JR (2000) Hypocretin-1 modulates rapid eye movement sleep through activation of locus ceruleus neurons. J Neurosci 20:7760-7765.

Brisbare-Roch C, Dingemanse J, Koberstein R, Hoever P, Aissaoui H, Flores S, Mueller C, Nayler O, van GJ, de Haas SL, Hess P, Qiu C, Buchmann S, Scherz M, Weller T, Fischli W, Clozel M, Jenck F (2007) Promotion of sleep by targeting the orexin system in rats, dogs and humans. Nat Med 13:150-155.

Chemelli RM, Willie JT, Sinton CM, Elmquist JK, Scammell T, Lee C, Richardson JA, Williams SC, Xiong Y, Kisanuki Y, Fitch TE, Nakazato M, Hammer RE, Saper CB, Yanagisawa M (1999) Narcolepsy in orexin knockout mice: molecular genetics of sleep regulation. Cell 98:437-451.

Drummond SP, Brown GG (2001) The effects of total sleep deprivation on cerebral responses to cognitive performance. Neuropsychopharmacology 25:S68-S73.

Edgar DM, Dement WC, Fuller CA (1993) Effect of SCN lesions on sleep in squirrel monkeys: evidence for opponent processes in sleep-wake regulation. J Neurosci 13:1065-1079.

Fadel J, Deutch AY (2002) Anatomical substrates of orexindopamine interactions: lateral hypothalamic projections to the ventral tegmental area. Neuroscience 111:379-387.

Fronczek R, Overeem S, Lee SYY, Hegeman I, van Pelt J, van Duinen S, Lammers GJ, Swaab DF (2007) Hypocretin (orexin) loss in Parkinson's disease. Brain 130:1577-1585.

Gerashchenko D, Kohls MD, Greco M, Waleh NS, Salin-Pascual R, Kilduff TS, Lappi DA, Shiromani PJ (2001) Hypocretin-2-saporin lesions of the lateral hypothalamus produce narcoleptic-like sleep behavior in the rat. J Neurosci 21:7273-7283.

Hanson LR, Martinez PM, Taheri S, Kamsheh L, Mignot E, Frey WH (2004) Intranasal administration of hypocretin 1 (orexin A) bypasses the bloodbrain barrier and targets the brain: a new strategy for the treatment of narcolepsy. Drug Deliv Tech: 4:1-10.

Hagan JJ, Leslie RA, Patel S, Evans ML, Wattam TA, Holmes S, Benham CD, Taylor SG, Routledge C, Hemmati P, Munton RP, Ashmeade TE, Shah AS, Hatcher JP, Hatcher PD, Jones DN, Smith MI, Piper DC, Hunter AJ, Porter RA, Upton N (1999) Orexin A activates locus coeruleus cell firing and increases arousal in the rat. Proc Natl Acad Sci USA 96:10911-10916.

Hampson RE, Pons TP, Stanford TR, Deadwyler SA (2004) Categorization in the monkey hippocampus: a possible mechanism for encoding information into memory. Proc Natl Acad Sci USA 101:3184-3189.

Hara J, Beuckmann CT, Nambu T, Willie JT, Chemelli RM, Sinton CM, Sugiyama F, Yagami K, Goto K, Yanagisawa M, Sakurai T (2001) Genetic ablation of orexin neurons in mice results in narcolepsy, hypophagia, and obesity. Neuron 30:345-354.

Horvath TL, Peyron C, Diano S, Ivanov A, Aston-Jones G, Kilduff TS, van den Pol A (1999) Hypocretin (orexin) activation and synaptic enervation of the locus coeruleus noradrenergic system. J Comp Neurol 415:145-159.

John J, Wu MF, Siegel JM (2000) Systemic administration of hypocretin-1 reduces cataplexy and normalizes sleep and waking durations in narcoleptic dogs. Sleep Res Online 3:23-28.

John J, Wu M-F, Kodama T, Siegel JM (2003) Intravenously administered hypocretin-1 alters brain amino acid release: an in vivo microdialysis study in rats. J Physiol (Lond) 548 2:557-562.

Kastin AJ, Akerstrom V (1999) Orexin A but not orexin B rapidly enters brain from blood by simple diffusion. J Pharmacol Exp Ther 289:219-223

Kastin AJ, Pan W, Maness LM, Banks WA (1999) Peptides crossing the blood-brain barrier: some unusual observations. Brain Res 848:96-100.

Kennedy C, Sakurada O, Shinohara M, Jehle J, Sokoloff L (1978) Local cerebral glucose utilization in the normal conscious macaque monkey. Ann Neurol 4:293-301.

Kilduff TS, Peyron C (2000) The hypocretin/orexin ligand-receptor system: implications for sleep and sleep disorders. Trends Neurosci 23:359-365.

Kiyashchenko LI, Mileykovskiy BY, Lai YY, Siegel JM (2001) Increased and decreased muscle tone with orexin (hypocretin) microinjections in the locus coeruleus and pontine inhibitory area. J Neurophysiol 85:2008-2016.

Kiyashchenko LI, Mileykovskiy BY, Maidment N, Lam HA, Wu MF, John J, Peever J, Siegel JM (2002) Release of hypocretin (orexin) during waking and sleep states. J Neurosci 22:5282-5286.

Lambe EK, Olausson P, Horst NK, Taylor JR, Aghajanian GK (2005) Hypocretin and nicotine excite the same thalamocortical synapses in prefrontal cortex: correlation with improved attention in rat. J Neurosci 25:5225-5229.

Lee MG, Hassani OK, Jones BE (2005) Discharge of identified orexin/hypocretin neurons across the sleep-waking cycle. J Neurosci 25:6716-6720.

Lin L, Faraco J, Li R, Kadotani H, Rogers W, Lin X, Qiu X, de Jong PJ, Nishino 
S, Mignot E (1999) The sleep disorder canine narcolepsy is caused by a mutation in the hypocretin (orexin) receptor 2 gene. Cell 98:365-376.

McFarland BJ, Beeson C (2002) Binding interactions between peptides and proteins of the class II major histocompatibility complex. Med Res Rev 22:168-203.

Mieda M, Willie JT, Hara J, Sinton CM, Sakurai T, Yanagisawa M (2004) Orexin peptides prevent cataplexy and improve wakefulness in an orexin neuron-ablated model of narcolepsy in mice. Proc Natl Acad Sci USA 101:4649-4654.

Mileykovskiy BY, Kiyashchenko LI, Siegel JM (2005) Behavioral correlates of activity in identified hypocretin/orexin neurons. Neuron 46:787-798.

Nambu T, Sakurai T, Mizukami K, Hosoya Y, Yanagisawa M, Goto K (1999) Distribution of orexin neurons in the adult rat brain. Brain Res 827:243-260.

Neter J, Wasserman W (1974) Applied linear statistical models, pp 465473. Chicago: Irwin.

Nishino S, Ripley B, Overeem S, Lammers GJ, Mignot E (2000) Hypocretin (orexin) deficiency in human narcolepsy. Lancet 355:39-40.

Peever JH, Lai YY, Siegel JM (2003) Excitatory effects of hypocretin-1 (orexin-A) in the trigeminal motor nucleus are reversed by NMDA antagonism. J Neurophysiol 89:2591-2600.

Peyron C, Tighe DK, van den Pol AN, de Lecea L, Heller C, Sutcliffe JG, Kilduff TS (1998) Neurons containing hypocretin (orexin) project to multiple neuronal systems. J Neurosci 18:9996-10015.

Peyron C, Faraco J, Rogers W, Ripley B, Overeem S, Charnay Y, Nevsimanova S, Aldrich M, Reynolds D, Albins R, Li R, Hungs M, Pedrazzoli M, Muralidhara P, Kucherlapti M, Fan J, Maki R, Lammers GJ, Bouras C, Kucherpapti R, Nishino S, Migonot E (2000) A mutation in a case of early onset narcolepsy and a generalized absence of hypocretin peptides in human narcoleptic brains. Nat Med 6:991-997.

Phelps ME, Huang SC, Hoffman EJ, Selin C, Sokoloff L, Kuhl DE (1979) Tomographic measurement of local cerebral glucose metabolic rate in humans with (F-18)2-fluoro-2-deoxy-D-glucose: validation of method. Ann Neurol 6:371-388.

Piper DC, Upton N, Smith MI, Hunter AJ (2000) The novel brain neuropeptide orexin-A, modulates the sleep-wake cycle of rats. Eur J Neurosci 12:726-730.

Porrino LJ, Daunais JB, Rogers GA, Hampson RE, Deadwyler SA (2005) Facilitation of task performance and removal of the effects of sleep deprivation by an ampakine (CX717) in nonhuman primates. PLoS Biol 3:e299.

Rasmussen K, Hsu MA, Yang Y (2007) The orexin-1 receptor antagonist SB-334867 blocks the effects of antipsychotics on the activity of A9 and A10 dopamine neurons: implications for antipsychotic therapy. Neuropsychopharmacology 32:786-792.

Siegel JM (2004) The neurotransmitters of sleep. J Clin Psychiatry 65 [Suppl $16]: 4-7$.

Smart D, Sabido-David C, Brough SJ, Jewitt F, Johns A, Porter RA, Jerman JC (2001) SB-334867-A: the first selective orexin-1 receptor antagonist. Br J Pharmacol 132:1179-1182.
Soffin EM, Evans ML, Gill CH, Harries MH, Benham CD, Davies CH (2002) SB-334867-A antagonizes orexin mediated excitation in the locus coeruleus. Neuropharmacology 42:127-133.

Sokoloff L, Reivich M, Kennedy C, Des Rosiers MH, Patlak CS, Pettigrew KD, Sakurada O, Shinohara M (1977) The $\left[{ }^{14} \mathrm{C}\right]$ deoxyglucose method for the measurement of local cerebral glucose utilization: theory, procedure, and normal values in the conscious and anesthetized albino rat. J Neurochem 28:897-916.

Taheri S, Sunter D, Dakin C, Moyes S, Seal L, Gardiner J, Rossi M, Ghatei M, Bloom S (2000) Diurnal variation in orexin A immunoreactivity and prepro-orexin mRNA in the rat central nervous system. Neurosci Lett 279:109-112.

Takikawa S, Dhawan V, Spetsieris P, Robeson W, Chaly T, Dahl R, Margouleff D, Eidelberg D (1993) Noninvasive quantitative fluorodeoxyglucose PET studies with an estimated input function derived from a populationbased arterial blood curve. Radiology 188:131-136.

Thannickal TC, Moore RY, Nienhuis R, Ramanathan L, Gulyani S, Aldrich M, Cornford M, Siegel JM (2000) Reduced number of hypocretin neurons in human narcolepsy. Neuron 27:469-474.

Thannickal TC, Lai YY, Siegel JM (2007) Hypocretin (orexin) cell loss in Parkinson's disease. Brain 130:1586-1595.

Thomas M, Sing H, Belenky G, Holcomb H, Mayberg H, Dannals R, Wagner H, Thorne D, Popp K, Rowland L, Welsh A, Balwinski S, Redmond D (2000) Neural basis of alertness and cognitive performance impairments during sleepiness. I. Effects of $24 \mathrm{~h}$ of sleep deprivation on waking human regional brain activity. J Sleep Res 9:335-352.

Trombetta ES, Mellman I (2005) Cell biology of antigen processing in vitro and in vivo. Annu Rev Immunol 23:975-1028.

van den Pol AN (1999) Hypothalamic hypocretin (orexin): robust innervation of the spinal cord. J Neurosci 19:3171-3182.

van den Pol AN, Gao XB, Obrietan K, Kilduff TS, Belousov AB (1998) Presynaptic and postsynaptic actions and modulation of neuroendocrine neurons by a new hypothalamic peptide, hypocretin/orexin. J Neurosci 18:7962-7971.

Vittoz NM, Berridge CW (2006) Hypocretin/orexin selectively increases dopamine efflux within the prefrontal cortex: involvement of the ventral tegmental area. Neuropsychopharmacology 31:384-395.

Woods RP, Mazziotta JC, Cherry SR (1993) MRI-PET registration with automated algorithm. J Comput Assist Tomogr 17:536-546.

Wu M-F, John J, Maidment N, Lam HA, Siegel JM (2002) Hypocretin release in normal and narcoleptic dogs after food and sleep deprivation, eating, and movement. Am J Physiol 283:1079-1086.

Yoshida Y, Fujiki N, Nakajima T, Ripley B, Matsumura H, Yoneda H, Mignot E, Nishino S (2001) Fluctuation of extracellular hypocretin-1 (orexin A) levels in the rat in relation to the light-dark cycle and sleep-wake activities. Eur J Neurosci 14:1075-1081.

Zeitzer JM, Buckmaster CL, Parker KJ, Hauck CM, Lyons DM, Mignot E (2003) Circadian and homeostatic regulation of hypocretin in a primate model: implications for the consolidation of wakefulness. J Neurosci 23: 3555-3560. 